\title{
Surgical outcome of strabismus
}

\author{
Sabina Shrestha', Aparajita Manoranjan ${ }^{1}$, Sushan Shrestha ${ }^{2}$. \\ ${ }^{1}$ Nepal Eye Hospital, Kathmandu, ${ }^{2}$ Manmohan Memorial Institute of Health Sciences, \\ Kathmandu
}

\begin{abstract}
Introduction: Strabismus is encountered daily by paediatric ophthalmologists and orthoptists in their practice. Strabismus and amblyopia affect $5 \%$ of the population. The aim of the study was to determine the surgical outcome of strabismus.

Methods: It was a prospective study conducted at Nepal Eye Hospital from 2010 to 2011 with the sample size of 40. Patients undergoing strabismus surgery either for esotropia or exotropia were included in the study. Detailed preoperative and postoperative orthoptic evaluation of all the patients was done apart from the anterior and posterior segment examination and the surgical outcome was assessed.

Results: Forty patients of which $52.5 \%$ males and $47.5 \%$ females with mean age of 21.025 years underwent strabismus surgery. Manifest divergent squint was present in $61 \%$, manifest convergent squint in $38 \%$ and intermittent squint in $5 \%$ of patients. $87.5 \%$ underwent 2 muscle surgery, $10 \%$ underwent 3 muscle surgery and $2.5 \%$ underwent single muscle surgery. Postoperative deviation for near was $0 \Delta$ in $10 \%, 2-8 \Delta$ in $37.5 \%$ and $10-15 \Delta$ in $27.5 \%$. Similarly, postoperative deviation for distance was $0 \Delta$ in $22 \%, 2-8 \Delta$ in $27 \%$ and $10-15 \Delta$ in $22 \%$. Binocular single vision was present in $50 \%$ patients preoperatively and $53 \%$ patients postoperatively.

Conclusions: Though cosmesis has been improved in most of the patients after strabismus surgery, binocular single vision and stereopsis improved in very minimal percentage of patients as the surgery was done after the age of visual maturation in most of the cases. This accentuates the need for strabismus surgery within the years of cortical plasticity.
\end{abstract}

Keywords: amblyopia, binocular single vision, strabismus, surgical outcome.

\section{INTRODUCTION}

Strabismus and amblyopia affect approximately 5\% of the population'. Strabismus is predominantly a disorder of childhood and its management, particularly the treatment of strabismic amblyopia is concentrated in the first decade ${ }^{2}$. Although continued monitoring of vision and periodic patching may be required through most of the first decade in patients with strabismus, it is the early start of treatment that has reduced the prevalence of deep seated amblyopia and eccentric fixation ${ }^{3}$. The manifestations of childhood strabismus do extend into the teenage and adult years. Adult strabismus patients may have had childhood strabismus and even undergone strabismus surgery when they are younger. These adult patients have many of the sensory adaptation seen in children with strabismus, including suppression. Frequently, the lack of binocularity and other related sensory adaptations simplify the task of realignment, reducing the potential for diplopia. Impaired binocularity in these patients may make alignment unstable in the long run ${ }^{4}$.

\section{METHODS}

Patients who underwent squint surgery, either for committant esotropia or exotropia were included in the study. The study site was Nepal Eye Hospital, Tripureshwor, Kathmandu. The study was conducted over a period of one year (2010-2011).Convenient sampling was done and informed consent was taken from all the patients for enrollment in the study and

\footnotetext{
Correspondence:

Dr. Sabina Shrestha

Nepal Eye Hospital, Kathmandu, Nepal

Ph: 9841287373

Email: sabina_drs@hotmail.com
} 
surgery.

Detailed history of the patients including duration of deviation, family history of squint, history of ocular trauma, birth history, history of wearing glasses and history of previous ocular surgery were taken.

Pre-operative orthoptic evaluation included test for visual acuity, extra ocular movements, Hirschberg test, cover test, prism cover test and Krimsky along with test for binocular single vision and post operative diplopia measurement preoperatively. Similarly, post-operative orthoptic evaluation included measurement of visual acuity, extra ocular movements, cover test, prism cover test and test for binocular single vision.

Data pertaining to patient demographics and clinical examination findings were entered in a especially designed performa. Data were analyzed using SPSS program (version 16).

\section{RESULTS}

A total of 40 patients underwent strabismus surgery from April 2011 to March 2012.

Age varied from a minimum of 3 years to a maximum of 56 years with a mean of 21.025 years.

Regarding the gender distribution, females were $52.5 \%$ and males were $47.5 \%$. 27.5\% were using spectacles prior to the squint surgery. History of ocular trauma was present in $17 \%$ of patients.

Similarly, abnormal head posture was present in $10 \%$ of patients. Extra ocular movements were full in $67.5 \%$ right eyes and $27.5 \%$ left eyes.

Regarding the distribution of patients according to visual acuity, $77.5 \%$ had visual acuity $6 / 6-6 / 18,17.5 \%$ had visual acuity of $<6 / 60$ and $5 \%$ had visual acuity of 6/24-6/60 prior to surgery.

Regarding the distribution of squint, divergent squint was present in $61 \%$, convergent squint in $34 \%$ and intermittent exotropia in $5 \%$ of the patients. $35 \%$ cases had alternate component of strabismus with good visual acuity and $7.5 \%$ cases had strabismic amblyopia.

Anterior segment was abnormal in 12\% right eyes and 15\% left eyes. Those having abnormal anterior segment, $10 \%$ had corneal opacity, 5\% were aphakic and $2.5 \%$ had partially absorbed cataract. Fundus evaluation showed abnormal fundus in 10\% right eyes and $15 \%$ left eyes.

\section{Figure I: Distribution of muscle surgery}

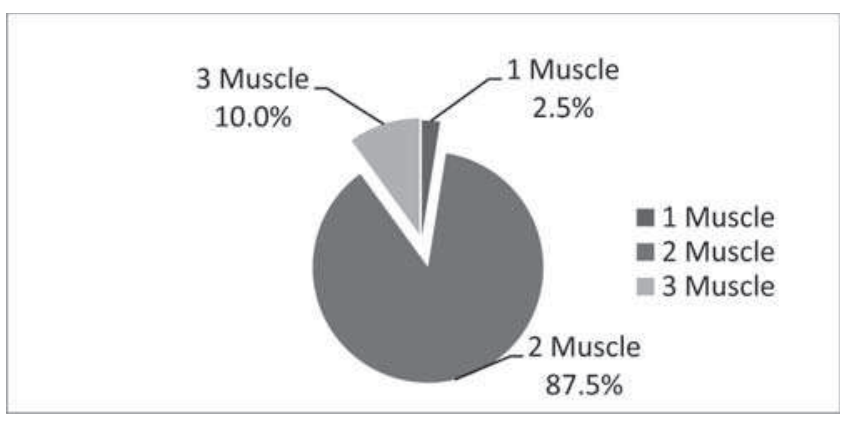

$85 \%$ underwent recess-resect procedure, $7.5 \%$ underwent bimedial resection and lateral recession, $5 \%$ underwent inferior oblique recession along with recess-resect procedure and $2.5 \%$ underwent single muscle surgery (medial rectus resection).

Pre operative deviation ranged from 25 to 85 prism dioptres $(\Delta)$ with $47.5 \%$ in the group $46-65 \Delta$. After surgery, deviation was $0 \Delta$ in $22.5 \%, 2-8 \Delta$ in $55 \%$ and $10-15 \Delta$ in $22.5 \%$.

Table I(A): Distribution of deviation (pre operative)

\begin{tabular}{|l|c|c|c|}
\hline $\begin{array}{c}\text { Amount of Deviation } \\
\text { (in prism dioptres) }\end{array}$ & $25-45 \Delta$ & $46-65 \Delta$ & $66-85 \Delta$ \\
\hline Percentage & $37.5 \%$ & $47.5 \%$ & $15 \%$ \\
\hline
\end{tabular}

Table I(B): Distribution of deviation (post operative)

\begin{tabular}{|c|c|c|c|}
\hline $\begin{array}{c}\text { Amount of Deviation } \\
\text { (in prism dioptres) }\end{array}$ & $0 \Delta$ & $2-8 \Delta$ & $10-15 \Delta$ \\
\hline Percentage & $22.5 \%$ & $55 \%$ & $22.5 \%$ \\
\hline
\end{tabular}


Figure II: Distribution of Binocular Single Vision

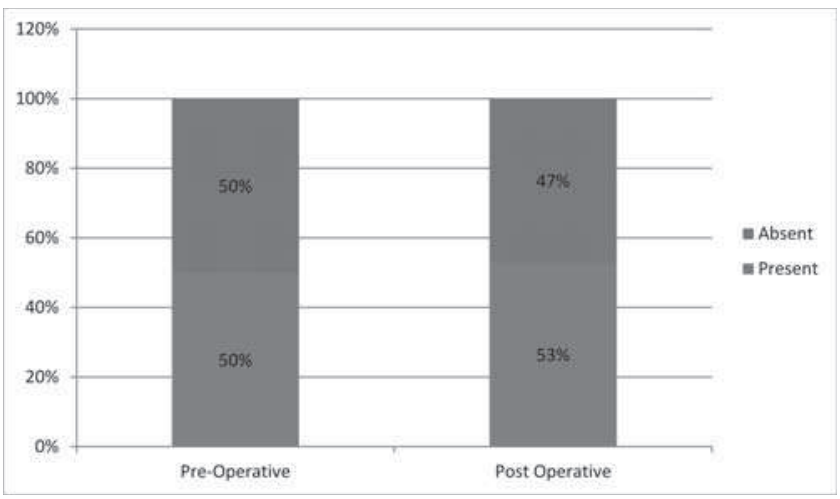

Figure III: Distribution of patients according to last follow up

Binocular single vision was present among $50 \%$ of patients pre-operatively and among $53 \%$ of patients post operatively.

Last follow-up time varied from 1 month to 10 months with $47.5 \% 1$ month follow-up.

\section{DISCUSSION}

Following strabismus surgery we expect to have perfect results. The critical period for improving vision and binocular single vision is well defined. For the functional success of strabismus surgery, alignment must be perfect, suppression must no longer be present and binocular single vision with good fusion and stereopsis should be present. However, after critical period, we expect to have perfect alignment for cosmetic purpose.

Strabismus can be present either from birth or acquired during early childhood or adulthood. Strabismus surgery in childhood during the period of cortical plasticity can restore binocular single vision and stereopsis. Rogers et al reported an improvement in fine motor skills in $35 \%$ of children with congenital esotropia after early surgery ${ }^{7}$.

Although the most common functional benefits from strabismus surgery in the adult patient are restoration of binocular vision and elimination of head posture, unexpected sensory fusion is possible after excellent postoperative motor alignment ${ }^{5}$.

Apart from cosmesis, the three major reasons to correct adult strabismus are restoration of binocular fusion and elimination of diplopia, expansion of binocular visual field in patient with esotropia ${ }^{6}$ and improvement in psychsocial functioning?.
In a study by Kushner \& Morton, in a series of 359 adults who underwent surgery for long standing constant strabismus, $86 \%$ of patient showed binocular response with the Bagolini lens test almost immediately after surgery ${ }^{8}$.

According to Thomas Satish, a good surgical outcome can be obtained in large-angle strabismus with a single surgical procedure though a randomized controlled study needs to be done'.

Preoperative deviation and refractive errors were proved to be significant factors influencing a favourable outcome in patients surgically with exotropia ${ }^{10}$.

In a study by Mets MB, the benefits of surgical correction of strabismus in adults include improvement in binocular function as seen in $42 \%$ of the patients ${ }^{11}$.

In a study by Garabaghi D \& Azadeh M, even after delayed alignment of eyes in patients with infantile or early childhood strabismus, some degrees of stereopsis can be achieved in most cases ${ }^{12}$.

However, in the present study, binocular single vision improved in only $3 \%$ of cases. The contributing factors for the same may be firstly, age less than 8 was only in three cases; secondly, anterior segment was abnormal in $12 \%$ right eyes and $15 \%$ left eyes and posterior segment was abnormal in 10\% right eyes and $15 \%$ left eyes.

\section{CONCLUSIONS}

Strabismus surgery performed in adult life though may be cosmetically good, binocular single vision is always lacking, therefore, squint surgery within the critical period needs to be advocated.

\section{REFERENCES}

1. Nelson, B. Paediatric Ophthalmology. Philadelphia: WB Saunders, 1984:110.

2. Parks, M.M.Strabismus: An overview. In:Spaeth, G.L., ed. Modern Concepts of Eye Care for Children. New Jersey: Slack, 1986:51.

3. Ching FC, Parks MM, Friendly DS. Practical management of amblyopia. J Pediatr Ophthalmol Strabismu. 1986;23:12. PMid:3950836

4. Monte D. Mills and Stephen J. Fricker.Adult strabismus. In: Albert \& Jakobiec, Azar, Gragoudas - Principle and Practice of Ophthalmology. Vol. 5. 2nd ed. Pennsylvania, WB Saunders Company. 
2000:4367-79.

5. Paula M. Edelman, C.O. Functional benefit of adult strabismus surgery. Amer. Orthoptic J. 2010;(60):143-7

6. Satterfield D, Keltner JL, Morrison TB. Psycholosocial aspects of strabismus study. Arch Ophthalmol. 1993;111:1100-5. http://dx.doi. org/10.1001/archopht.1993.01090080096024 PMid:8166786

7. Rogers GL, Chazan S, Fellows R, Tsou BH. Strabismus surgery and its effects upon infant development in congenital strabismus. Ophthalmology. 1982;89:479-83. http://dx.doi. org/10.1016/S0161-6420(82)34766-1

8. Kushner BJ, Morton GV. Postoperative binocularity in adults with longstanding strabismus. Ophthalmology. 1992; 99:316-9. http://dx.doi.org/10.1016/S0161-6420(92)319700

9. Thomas S., Guha S. Large angle strabismus: Can a single surgical procedure achieve a successful outcome? Strabismu. 2010;18(4):129-36. http:// dx.doi.org/10.3109/09273972.2010.525778 PMid:21091333

10. Acun Gezer, Fazil Sezen, Nail Sahri, Nilufer Gozum. Factors influencing the outcome of strabismus surgery in patients with exotropia. JAAPOS. 2004;8(1):56-60. ttp:// dx.doi.org/10.1016/j.jaapos.2003.08.006 PMid:14970801

11. Mets MB, Beauchamp C, Haldi BA. Binocularity following surgical correction of strabismus in adult. Trans Am Ophthalmol Soc. 2003;101:2017. PMid: 14971578

12. Garabaghi D, Azadeh M. Binocular vision and stereopsis following delayed strabismus surgery. Iranian Journal of Ophthalmology. 2006;19(2):4650. 